\title{
O CURSO DE PEDAGOGIA E O PROCESSO DE FORMAÇÃO DO PEDAGOGO NO BRASIL: PERCURSO HISTORICO E MARCOS LEGAIS
}

\author{
A. P. P. ARANTES ${ }^{*}$ e R. A. GEBRAN
Universidade do Oeste Paulista (Unoeste)
dirfama@yahoo.com.br ${ }^{*}$ \\ Artigo submetido em setembro/2013 e aceito em dezembro/2014 \\ DOI: $10.15628 /$ holos.2014.1643
}

\section{RESUMO}

Este estudo tem como objetivo compreender o percurso histórico do curso de Pedagogia no Brasil pela via dos seus marcos legais, a partir do ano de 1939 até os dias atuais. A pesquisa caracteriza-se por meio de uma abordagem qualitativa, utilizando como procedimento técnico a pesquisa bibliográfica e a pesquisa documental. Foram analisadas as quatro principais regulamentações do curso de Pedagogia, a saber: Decreto-Lei no 1.190/1939; Parecer no 251/1962; Parecer no 252/1969 e Resolução CNE/CP no 1/2006. A partir das análises destes marcos legais percebemos que houve, desde a criação do curso de Pedagogia até hoje, uma incerteza sobre o propósito e a função do pedagogo, o que influenciou o desenvolvimento da licenciatura em Pedagogia, fazendo com que esta ocupasse um lugar periférico no contexto das licenciaturas, porque eram percebidas como cursos de segunda categoria. Diante desse vasto e contraditório campo de atuação desse profissional, questionamos: o que é realmente ser pedagogo?

PALAVRAS-CHAVE: Legislação Educacional, Curso de Pedagogia, Formação do Pedagogo.

\section{THE PEDAGOGY COURSE AND THE PROCESS OF FORMATION EDUCATOR IN BRAZIL: WAY HISTORICAL AND LEGAL}

\begin{abstract}
Brazil via their legal frameworks, since the emergence of this course in 1939 to today. The research was developed in the qualitative approach, using the procedure as bibliographic and documentary research. Were analyzed the four main regulations of the pedagogy course, being: Decree-Law no 1.190/1939; Legal Opinion no 251/1962; Legal Opinion no 252/1969 and Resolution CNE/CP $\mathrm{n}$ - 1/2006. From the analysis of these legal frameworks realized there was since the
\end{abstract}

creation of the pedagogy course until today, uncertainty about the purpose and function of the pedagogue, which influenced the development of the pedagogy course, causing it to occupy a peripheral place in the context of graduation, because they were perceived as second category. Given this vast and contradictory this professional field of endeavor, I ask, what is really being pedagogue?

KEYWORDS: Educational Legislation. Pedagogy Course, Teacher Training. 


\section{INTRODUÇÃO}

O Curso de Pedagogia no Brasil foi concebido no contexto da criação das Faculdades de Filosofia, Ciência e Letras, em 1939, como consequência da preocupação com a formação de docentes para o curso normal. Desde a sua criação tem sido marcado pelas dicotomias entre professor e especialista, bacharelado e licenciatura, generalista e especialista, técnico em educação e professor.

Este estudo tem como objetivo compreender o percurso histórico do curso de Pedagogia no Brasil pela via dos seus marcos legais, a saber: Decreto-Lei no 1.190/1939; Parecer no 251/1962; Parecer no 252/1969 e Resolução CNE/CP n 1/2006.

A pesquisa caracteriza-se por meio de uma abordagem qualitativa, utilizando como procedimento técnico a pesquisa bibliográfica e a pesquisa documental.

\section{DESENVOLVIMENTO}

O Decreto-Lei n.o 1.190, de 4 de abril de 1939, ao organizar a Faculdade Nacional de Filosofia, criou também o curso de Pedagogia com três anos de bacharelado e mais um ano que compreendia o curso de Didática para a formação do professor, então em três anos formava-se o bacharel e no quarto ano (Curso de Didática) era conferido o diploma de licenciado. Esta configuração da matriz curricular do Curso de Pedagogia foi denominada de "modelo 3+1", o qual foi amplamente explorado na formação de professores em nível superior.

O currículo Implementado para o novo curso possuía as seguintes disciplinas obrigatórias como mostra Saviani (2008, p. 39):

10 ano: Complementos da matemática, história da filosofia, sociologia, fundamentos biológicos da educação, psicologia educacional.

2ㅇ ano: Psicologia educacional, estatística educacional, história da educação, fundamentos sociológicos da educação, administração escolar.

3o ano: Psicologia educacional, história da educação, administração escolar, educação comparada, filosofia da educação.

O curso de Didática tinha a duração de um ano e era composta pelas seguintes disciplinas: "Didática geral, didática especial, psicologia educacional, fundamentos biológicos da educação, fundamentos sociológicos da educação, administração escolar". (SAVIANI, 2008, p. 39-40)

Esta organização curricular favorecia a dicotomia entre o conteúdo e o método e entre a teoria e a prática. Segundo Brzezinski (1996, p. 44) "o bacharelado em Pedagogia percorria um caminho oposto aos demais bacharelados. Estudavam-se generalidades com conteúdo de base e superpunha-se o específico num curso à parte - o de didática da Pedagogia".

No que tange ao campo de trabalho do pedagogo, o artigo 51, alínea ' $c$ ' do Decreto-Lei n. $01.190 / 1939$ estipulava que, a partir de 1 을 de janeiro de 1943, seria exigido o grau de bacharel em pedagogia para os cargos de técnico de educação. Quanto aos licenciados, poderiam atuar como professores da Escola Normal, responsável pela formação dos professores primários. 
Porém existia uma incerteza quanto este campo de trabalho conforme explicita Chaves (1981, p. 48), pois o Licenciado em Pedagogia tinha direito de lecionar em Escolas Normais; entretanto, "o Bacharel em Pedagogia, sem a formação complementar do Curso de Didática, era conhecido como um 'técnico em educação', embora nunca houvessem sido definidas de maneira precisa suas funções".

Silva (2006, p.64), ao discorrer sobre o propósito e as incertezas da função do pedagogo afirma que faltava alguma "referência sobre a sua destinação profissional, não se percebia, na época, as ocupações a serem preenchidas por este novo profissional". As incertezas da função do pedagogo influenciam o desenvolvimento da licenciatura em Pedagogia, pois, segundo Brzezinski (1996, p. 46):

\begin{abstract}
Marcado por uma pseudo-identidade, passo a passo, o curso de Pedagogia foi ocupando lugar periférico no contexto das licenciaturas que já eram periféricas no elenco dos demais cursos superiores, porque percebidas como cursos de segunda categoria. Os professores mais bem preparados na universidade não se dedicavam ao curso de Pedagogia.
\end{abstract}

A estrutura curricular para o curso de Pedagogia definida pelo Decreto-Lei n.01.190/1939 prevaleceu, segundo Saviani (2008) até a aprovação da LDB 4.024/1961.

A Lei 4.024/1961 - primeira Lei de Diretrizes e Bases da Educação - LDB, declarava no art. 70 que "o currículo mínimo e a duração dos cursos que habilitem à obtenção de diploma capaz de assegurar privilégios para o exercício da profissão liberal serão fixados pelo Conselho Federal de Educação".

A partir daí surge o segundo marco legal do Curso de Pedagogia: o Parecer do Conselho Federal de Educação (CFE) № 251/1962, de autoria do conselheiro Valnir Chagas foi elaborado em atendimento à Lei 4.024/1961.

O Parecer CFE no 251/1962 estabeleceu os conteúdos mínimos para o curso de Pedagogia - bacharelado que era composto por sete matérias conforme apresentado por Silva (2006, p.37) sendo algumas obrigatórias, como Psicologia da Educação, Sociologia Geral, Sociologia da Educação, História da Educação, Filosofia da Educação e Administração Escolar e outras matérias opcionais, como Biologia, História da Filosofia, Estatística, Métodos e Técnicas de Pesquisa Pedagógica, Cultura Brasileira, Educação Comparada, Higiene Escolar, Currículos e Programas, Técnicas Audiovisuais de Educação, Teoria e Prática da Escola Média e Introdução à Orientação Educacional. Para a licenciatura, as matérias que deveriam ser cursadas eram: Didática e Prática de Ensino.

O Parecer CFE no 251/1962 reafirma a estrutura padrão dos cursos de licenciatura no formato $3+1$, proposta ao curso de Pedagogia, desde a sua regulamentação inicial por meio do Decreto - Lei no 1.190/1939. Brzezinski (1996, p.56) ressalta a posição contrária dos educadores sobre o currículo mínimo proposto pelo Parecer CFE no 251/1962, pois consideravam uma "camisa de força que uniformizava todos os currículos sem respeitar a diversidade do País".

A autora faz menção ainda, à formação técnica realizada nos cursos de Pedagogia, como reflexo da política planificada do modelo desenvolvimentista. 
A escola passou a formar profissionais treinados e instrumentalizados mediante "rações" de um saber fragmentado visando atingir cada vez mais a produtividade. Ao mesmo tempo, foi negada qualquer possibilidade de pensar, criticar ou criar. Houve, portanto, nesse momento uma supervalorização dos cursos que formavam apenas técnicos. A educação, neste contexto, transformou-se em treinamento. (BRZEZINSKI, 1996, p. 59)

Em 1968, por força da Lei no 5.540, o curso de Pedagogia deixou de fazer parte das Faculdades de Filosofia, uma vez que a seção de Pedagogia dentro da Faculdade de Filosofia deixa de existir. Então o curso de Pedagogia passa a ser oferecido pelas Faculdades de Educação, regulamentadas através do Parecer CFE no 252/1969 e da Resolução CFE no 2/1969, que estabeleciam as normas de seu funcionamento em conformidade com os princípios da Lei $5.540 / 1968$.

O Parecer CFE no 252/1969 de 11 de abril de 1969, também de autoria do professor Valmir Chagas, membro do Conselho Federal de Educação, foi acompanhado da Resolução CFE no. 2/1969, que se incumbiu de fixar o currículo mínimo e a duração do curso.

A estrutura curricular do curso foi dividida em duas partes: a comum, que era à base do curso, e a diversificada, que oferecia diversas habilitações de duração plena, compostas por Magistério das disciplinas pedagógicas na Escola Normal, Orientação Educacional; e de curta duração, Administração Escolar, Supervisão Escolar e Inspeção Escolar. As habilitações passaram a compor a parte final na estrutura do curso de Pedagogia, ao contrário do formato anterior composto por bacharelado e licenciatura.

O Parecer CFE 252/1969, no seu parágrafo 3. estabelece as condições para obtenção de habilitações específicas do Curso:

Art. 2. - O Currículo mínimo do curso de Pedagogia compreenderá uma parte comum a todas as modalidades de habilitação e outra diversificada em função de habilitações específicas.

$\S$ 3.․ - A parte diversificada compreenderá, segundo a modalidade de habilitação específica e conforme as possibilidades de cada Instituição, duas ou mais dentre as seguintes matérias e atividades, na forma do artigo 3.‥

A disciplina de Didática, antes optativa, passou a compor a parte comum do currículo, sob o argumento de que os pedagogos seriam, por princípio, professores da Escola Normal.

As disciplinas obrigatórias, que compunham o núcleo comum, atendendo à Resolução CFE no 2/1969, ficaram designadas como segue: Sociologia Geral, Sociologia da Educação, Psicologia da Educação, História da Educação, Filosofia da Educação e Didática.

Essa regulamentação manteve a formação de professores para o Ensino Normal e forma introduzidas oficialmente, as habilitações para formar os especialistas responsáveis pelo trabalho de planejamento, supervisão, administração e orientação educacional.

De acordo com Chaves (1981, p.54):

Aos egressos do curso de Pedagogia cabia o exercício das habilitações que Ihes asseguravam a atuação como orientador, supervisor, administrador e inspetor escolar, o exercício do magistério no ensino normal, tanto das disciplinas 
correspondentes às habilitações específicas quanto da parte comum do curso e o exercício do magistério na escola primária.

Analisando a escolha que o aluno deveria realizar durante o curso referente à função que desempenhariam, ou seja, a escolha de qual habilitação deveria cursar, Silva $(2006$, p.23) considera que tal mudança:

Era uma tendência que se intensificava na área da educação em geral: a de se estabelecer a correspondência direta e imediata entre currículo e tarefas a serem desenvolvidas em cada profissão, tendência esta bastante visível no contexto pós-golpe militar de 1964.

De acordo com o Parecer CFE no. 252/1969, o Curso de Pedagogia passou a conferir apenas o grau de licenciado, abolindo o de bacharel, pautado pelo núcleo central do curso que focava o pedagógico a serviço da docência. A didática, antes uma seção e, portanto, um curso à parte, se tornou disciplina obrigatória do curso.

Nesses termos, para alcançar uma habilitação, o candidato deveria comprovar experiência de magistério, o que foi alvo de regulamentação posterior (Parecer do CFE no. 867/1972).

Para a certificação das habilitações, o Parecer no 867/1972 estabeleceu a necessidade de comprovação de experiência docente de um ano para Orientação Educacional e um semestre para as demais habilitações. A obrigatoriedade da experiência docente determinada no Parecer no 867/72 pressupunha que o aluno do curso de Pedagogia já tivesse atuado como professor, ainda que não tivesse recebido a titulação para exercício de tal função (SILVA, 1999, p. 61)

Sobre à formação do pedagogo propostas pelas legislações da década de 60 e 70, Saviani (2008, p.51) enfatiza que:

O pedagogo foi taxado de generalista, pois se procurou privilegiar a formação de técnicos por meio das habilitações com funções supostamente bem específicas no âmbito das escolas e sistemas de ensino que configurariam um mercado de trabalho, demandando em consequência, os profissionais com uma formação específica que seria sugerida pelo curso de Pedagogia. Daí a reestruturação desse curso exatamente para atender a referida demanda.

Referindo-se à evolução dos estudos pedagógicos em nível superior Brzezinski (1996, p. 30) salienta que:

Desde os anos 30 até os anos 60, no Brasil, os estudos pedagógicos em nível superior, públicos e privados, tiveram uma evolução, via de regra, lenta e irregular, pois a educação é um dos setores da sociedade no qual os mecanismos sociais de resistência à mudança atuam com mais intensidade. A esta resistência acrescenta-se o desprestígio desta área de saber.

Durante os anos de 1973 a 1976, a autora explicita que várias indicações foram encaminhadas ao Conselho Federal de Educação - CFE definindo as normas, princípios, diretrizes e procedimentos para nortear a formação do profissional da educação no Brasil. Estas novas 
propostas ao CFE, em parte, são frutos da Reforma do Ensino Fundamental e Médio promovida pela Lei 5.692/1971, também formulada sob a influência do "eterno" conselheiro Valnir Chagas.

Considerando o final dos anos 1970 e início dos anos de 1980. Libâneo (2007, p. 12-13) acredita que este período:

[...] marca o início da campanha pela transformação do curso de Pedagogia num curso de formação de professores. O arrefecimento do controle político e da censura pelos militares, junto com resistências dos setores de esquerda organizados, favoreceu a produção de pesquisas e publicações no campo da educação contra práticas autoritárias e ideológicas no regime militar. Disso resultou a realização, em São Paulo, na PUC, da I Conferência Brasileira de Educação (CBE), quando já existia o chamado Comitê Pró-Participação na formação do educador, com a participação de nomes expressivos das faculdades de Educação. O que movia esse comitê eram as críticas aos Parecer 252/69 e às indicações de Valnir Chagas, tidos como tecnicistas, destinados a consolidar a educação tecnista baseada na racionalidade técnica, na busca de eficiência e produtividade, contra um educação crítica e transformadora. Havia um alvo paralelo das críticas, que era a Lei 5.540, que regulava todo o ensino superior na perspectiva tecnicista.

Sobre a evolução do curso de licenciatura em Pedagogia no período compreendido entre a década de 1960 até 1980 Brzezinski (1996) informa que as faculdades mantinham o monopólio deste curso, uma vez que absorviam $88,7 \%$ dos cursos de licenciatura em pedagogia, restando as universidades apenas $11,3 \%$ da oferta total.

Ainda segundo a autora, os dados acima demonstram o "descompromisso do Estado educador com a sociedade civil, que financiava antecipadamente a educação" (p.50).

Para Arantes e Gebran (2013) os anos de 1980 e início de 1990 foram marcados por discussões sobre a formação do pedagogo, porém não alterou em termos legais a estruturação deste curso, que foi mantida seguindo o disposto no Parecer 252/69, que vigorou durante 27 anos, até a aprovação da LDB no. 9.394, de 20 de dezembro de 1996.

Na década de 1980 , os educadores engajados em discussões, debates, estudos e
pesquisas sobre a reformulação dos cursos que formam professores, com todas
as dificuldades, pressões e incertezas, passaram a lutar pela modificação de
práticas autoritárias brasileiras de formação de profissionais da educação que
contribuem para a manutenção do sistema vigente e deterioração do sistema
educacional e concomitantemente passaram a escrever a sua história.
(BRZEZINSKI, 1996, p. 83).

Na época em que a LDB no. 9.394/1996 foi sancionada, salienta Pereira (1999), havia o predomínio de políticas neoliberais impostas principalmente pelo Banco Mundial e pelo Fundo Monetário Internacional (FMI), as quais visavam à redução do Estado e o fortalecimento das leis de mercado em todos os setores da sociedade, incluindo o setor educacional.

Segundo Aguiar (2003), levando em consideração o quadro das políticas educacionais neoliberais e das reformas educativas, a educação constitui-se em elemento facilitador importante dos processos de acumulação capitalista e, em decorrência, a formação de 
professores ganha importância estratégica para a realização dessas reformas no âmbito da escola e da educação básica.

A LDB 9394/96, traz novos rumos para a educação e para os profissionais que nela atuam. O artigo 62 define o local e o nível da formação de professores para atuar na educação básica.

Art. 62. A formação de docentes para atuar na educação básica far-se-á em nível superior, em curso de licenciatura, de graduação plena, em universidades e institutos superiores de educação, admitida, como formação mínima para o exercício do magistério na educação infantil e nas quatro primeiras séries do ensino fundamental, a oferecida em nível médio, na modalidade Normal.

Donatoni e Gonçalves (2009, p.5) salientam que:

Em 1996, a nova LDB introduz indicadores para a formação de educadores/as para a educação básica e o curso de Pedagogia, assim como retoma a discussão da identidade com novas questões, dentre as quais, a de que o Curso Normal Superior apresenta especulações sobre o que tinha como função básica: a formação de docente. Assim, torna-se plausível a possibilidade de extinção do curso de Pedagogia, que o deixa numa posição ambígua; e a elaboração de suas propostas fica a cargo das universidades conforme suas interpretações da LDB. Logo, se falta regulamentação aos institutos superiores e às demais Instituições de Ensino Superior (IES), a tarefa de formação de professores/as se torna mais confusa.

A Lei 9394/1996 trás implícita uma descaracterização das habilitações até então existentes no curso de Pedagogia, uma vez que em seu artigo 64 não limita a formação do especialista de educação como tarefa única do curso de Pedagogia, apenas acena como uma das tarefas:

\begin{abstract}
A formação de profissionais de educação para administração, planejamento, inspeção, supervisão e orientação educacional para a educação básica, será feita em cursos de graduação em pedagogia ou em nível de pós-graduação, a critério da instituição de ensino, garantida, nesta formação, a base comum nacional.
\end{abstract}

A LDB 9394/1996, cria novos espaços para a formação de professores da Educação Básica, como os Institutos Superiores de Educação - ISEs, que oferecerão programas e cursos, entre os quais o Curso Normal Superior visando a formação de docentes para atuar na Educação Infantil e nas séries iniciais do Ensino Fundamental.

A criação dos ISEs, aos quais se atribui a responsabilidade da formação de todos os professores para a Educação Básica, sob a justificativa de integração espacial e pedagógica do processo formador, acabou exacerbando o dualismo que caracteriza o modelo de licenciatura vigente, ao separar a atividade de formação da atividade de produção de conhecimentos essenciais 'docência de cada área, desenvolvida no ambiente universitário e responsável pelos significativos avanços teóricos na área da Educação nos últimos trinta anos. (ANFOPE, 2002, p.3)

Brzezinski (1996, p.201) explicita a posição da Associação Nacional pela Formação dos Profissionais da Educação - Anfope no que tange à política de formação do pedagogo "deve 
constituir-se dos seguintes elementos: formação inicial de qualidade, condições de trabalho dignas e formação continuada como direito do profissional e dever da agência contratante".

Com a implantação da Lei 9.394/1996 foram homologados muitos outros textos legais em forma de Leis, Decretos, Portarias Ministeriais, Resoluções e Pareceres. Dentre estes vamos ater nesta pesquisa a explanação de alguns pontos referentes à normatização das Diretrizes Curriculares Nacionais para o curso de Pedagogia.

No processo de construção das Diretrizes Curriculares, existia uma divisão entre os interesses do Estado e do Movimento Nacional de Educadores como mostra Brzezinski (2001, p. 119)
O mundo do sistema ou oficial tem como expoente o princípio de políticas neoliberais e se reafirma em parcerias com organismos internacionais, já o mundo vivido ou mundo real construído na luta pelo Movimento Nacional de Educadores desde 1980, propõe a adoção de uma política global de formação e profissionalização docente.

A Resolução CP 01, de 30 de setembro de 1999 no seu artigo 1으 orienta a criação dos Institutos Superiores de Educação:

Art. 10 Os institutos superiores de educação, de caráter profissional, visam à formação inicial, continuada e complementar para o magistério da educação básica, podendo incluir os seguintes cursos e programas:

1 - curso normal superior, para licenciatura de profissionais em educação infantil e de professores para os anos iniciais do ensino fundamental;

II - cursos de licenciatura destinados à formação de docentes dos anos finais do ensino fundamental e do ensino médio;

III - programas de formação continuada, destinados à atualização de profissionais da educação básica nos diversos níveis;

IV - programas especiais de formação pedagógica, destinados a portadores de diploma de nível superior que desejem ensinar nos anos finais do ensino fundamental ou no ensino médio, em áreas de conhecimento ou disciplinas de sua especialidade, nos termos da Resolução CNE no 2/97;

Martelli e Manchope (2004, p. 14) afirmam que:

A criação dos Institutos Superiores de Educação, desdobramentos das políticas publicas educacionais, impregnada de princípios neoliberais, resgata a superada dicotomia entre o bacharelado e a licenciatura - impulsiona o esvaziamento do curso de Pedagogia e a supressão da docência como sua base, transformando- o em bacharelado-, fazendo transparecer a centralização na docência.

Com a publicação do Decreto № 3.276 de 06 de dezembro de 1999, que dispõe sobre a formação em nível superior de professores para atuar na educação básica, fica claro em seu art. 3으 § 2으, que "a formação em nível superior de professores para a atuação multidisciplinar, destinada ao magistério na educação infantil e nos anos iniciais do ensino fundamental far-se-á exclusivamente em cursos normais superiores". 
Porém esta redação foi alterada pelo Decreto no3554 de 07 de agosto de 2000, que substitui o termo exclusivamente por preferencialmente. O Decreto $\mathrm{n} \times 3554 / 2000$, em seu art.1으, parágrafo 2으, estabelece o curso normal superior como espaço preferencial para a formação de professores da Educação Básica:

A formação em nível superior de professores para a atuação multidisciplinar destinada ao magistério na educação infantil e nos anos iniciais do ensino fundamental far-se-á, preferencialmente, em cursos normais superiores.

Referindo-se ao Decreto n3554/2000, Brzezinski (2001, p.119) acredita que:

Diante de circunstâncias tão adversas das políticas educacionais do atual governo que investem contra a formação de professores na Universidade, garantida desde 1931 pelo Estatuto das Universidades Brasileiras, deve-se admitir que o Decreto n. 3554/2000 "foi uma meia-vitória, mas foi uma vitória". Essa vitória se efetivou pela ação política imediata de denúncia feita pela sociedade civil organizada em entidades educacionais de representatividade democrática. A meia-vitória diz respeito à substituição do termo "exclusivamente" imposto pelo Decreto n. 3276/99 por "preferencialmente"

Segundo Arantes e Gebran (2013) a regulamentação do curso Normal Superior ocorreu de modo fragmentado, possuindo deliberações nas determinações referentes ao ISE, aos cursos de licenciatura e formação docente para a educação infantil e os anos iniciais do ensino fundamental e nas Diretrizes Curriculares Nacionais para a Formação de Professores da Educação Básica em nível Superior.

Sobre os documentos norteadores referentes à formação de professores, Martelli e Manchope (2004, p. 16) pressupoem que:

Configura-se um paradoxo na LDB 9394/96 e nos seus documentos normatizadores. De um lado, cria os Institutos Superiores de Educação (Resolução 1/99), define o Curso Normal Superior como espaço preferencial para a formação dos professores da Educação Básica (Decreto 3.554/2000) e preserva esta função ao curso de Pedagogia (Art.62 da LDB 9394/96), tendo como consequência dois cursos em espaços distintos ou não, a mesma atribuição acadêmica.

Em 18 de fevereiro de 2002, com a publicação da Resolução CNE/CP no.01, instituiu-se as diretrizes curriculares nacionais para a formação de professores da educação Básica, em nível superior, curso de licenciatura de graduação plena.

As diretrizes curriculares nacionais do curso de Pedagogia foram encaminhadas para homologação em 20/12/2005, através do Parecer CNE/CP no 5/2005.

A finalidade do curso de Pedagogia, definida no Projeto de Resolução anexo ao Parecer CNE/CP no 5/2005 (p.6) compreende em:

Formação inicial para o exercício da docência na Educação Infantil e anos iniciais do Ensino Fundamental, nos cursos de Ensino Médio de modalidade Normal e em cursos de Educação Profissional, na área de serviços e apoio escolar, bem como em outras áreas nas quais sejam previstos os conhecimentos pedagógicos. 
Este Parecer traz como novidade, entre outras, a ruptura com os modelos curriculares anteriores do curso, em que conteúdos e disciplinas eram estabelecidos pelas diretrizes curriculares. A nova estrutura do curso de Pedagogia é constituída por três núcleos: o núcleo de estudos básicos, o núcleo de aprofundamento e diversificação de estudos e o núcleo de estudos integradores.

Os três núcleos de estudos, da forma como se apresentam, devem propiciar a formação daquele profissional que: cuida, educa, administra a aprendizagem, alfabetiza em múltiplaslinguagens, estimula e prepara para a continuidade do estudo, participar da gestão escolar, imprime sentido pedagógico a práticas escolares e não-escolares, compartilha os conhecimentos adquiridos em sua prática. (BRASIL, 2005, p.14).

Sem muitas alterações no Projeto de Resolução anexo ao Parecer CNE/CP no 5/2005, em 2006, foi finalmente promulgada a Resolução CNE/CP no 1; que fixa as diretrizes curriculares para o curso de Pedagogia, identificando-se assim como o quarto marco legal deste curso.

A estrutura curricular do curso permanece constituída pelos três núcleos - estudos básicos, aprofundamento e diversificação de estudos e o estudos integradores.

A estrutura do curso de Pedagogia, respeitadas a diversidade nacional e a autonomia pedagógica das instituições, constituir-se-á de:

I - um núcleo de estudos básicos que, sem perder de vista a diversidade e a multiculturalidade da sociedade brasileira, por meio do estudo acurado da literatura pertinente e de realidades educacionais, assim como por meio de reflexão e ações críticas [...]

II - um núcleo de aprofundamento e diversificação de estudos voltado às áreas de atuação profissional priorizadas pelo projeto pedagógico das instituições e que, atendendo a diferentes demandas sociais [...]

III - um núcleo de estudos integradores que proporcionará enriquecimento curricular [...]. Art 6o

No que se refere ao curso Normal Superior, esta resolução ofereceu uma opção em seu art. 11:

As instituições de educação superior que mantêm cursos autorizados como Normal Superior e que pretenderam a transformação em curso de Pedagogia [...] deverão elaborar novo projeto pedagógico, obedecendo ao contido nesta Resolução.

Sobre a formação do profissional pedagogo a Resolução CNE/CP no 1/2006, no seu artigo 4을 determina que:

O curso de Licenciatura em Pedagogia destina-se à formação de professores para exercer funções de magistério na Educação Infantil e nos anos iniciais do Ensino Fundamental, nos cursos de Ensino Médio, na modalidade Normal, de Educação Profissional na área de serviços e apoio escolar e em outras áreas nas quais sejam previstos conhecimentos pedagógicos.

Parágrafo único. As atividades docentes também compreendem participação na organização e gestão de sistemas e instituições de ensino, englobando: 
I - planejamento, execução, coordenação, acompanhamento e avaliação de tarefas próprias do setor da Educação;

II - planejamento, execução, coordenação, acompanhamento e avaliação de projetos e experiências educativas não-escolares;

III - produção e difusão do conhecimento científico-tecnológico do campo educacional, em contextos escolares e não-escolares.

Analisando o artigo 4으 da Resolução CNE/CP no 1/2006 Libâneo (2007, p.30) tece as seguintes considerações:

Por razões lógico-conceituais, o curso de Pedagogia pode incluir o curso de formação de professores de Educação infantil e dos anos iniciais do Ensino Fundamental, mas não ser reduzido a ele. (...) Não em nenhuma sustentação teórica, nem pela epistemologia, nem pela tradição da teoria pedagógica, a afirmação de que a base de formação do pedagogo é a docência. O raciocínio mais límpido diz que o campo da pedagogia é a reflexão sobre as práticas educativas, em sua diversidade, uma delas o ensino, ou seja, a docência.

Considerando como referencial as cinco modalidades de magistério definidas pela Resolução CNE/CP no 1/2006, a saber: Educação Infantil, Anos iniciais do Ensino Fundamental, cursos de Ensino Médio, na modalidade Normal, cursos de Educação Profissional na área de serviços e apoio escolar e em outras áreas nas quais sejam previstos conhecimentos pedagógicos, Libâneo (2007) considera que o texto legal faz referência a apenas à docência na Educação Infantil e nos anos iniciais do Ensino Fundamental. Na concepção do autor, às demais modalidades faltam orientações quanto às definições curriculares e as modalidades de diplomação.

Não se esclarece se os percursos curriculares são separados ou se há uma base comum que depois se ramifica em habilitações (o texto não menciona o termo habilitações nem outro equivalente). Do mesmo modo, o artigo que trata da formação dos profissionais da educação para administração, planejamento, supervisão, etc.(art.64 da Lei no. 9394/1996) em nível de pós-graduação está inteiramente desconectado dos demais artigos deixando dúvidas aos dirigentes de cursos de formação. Além disso, a resolução ignora a prescrição legal da LDBEN de que esta formação deve ser feita também em cursos de graduação em Pedagogia. (p.33)

Sobre a formação do pedagogo Soares e Bettega (2009, p.84) fazem a seguinte análise:

O Parecer CNE/CP $n^{\circ}$ 05/2005 exclui a formação do pedagogo na graduação,deixando a formação para o nível de pós-graduação, a Resolução CNE/CP n01/2006 que é idêntica ao Parecer 03/2006, depois de pressão da comunidade acadêmica, retoma a questão da formação do pedagogo no Art. 14. Porém a Resolução CNE/CP $n^{\circ}$ 01/2006 exclui gradativamente o pedagogo, pois o pedagogo pode ser formado no curso de Pedagogia, mas também em cursos de pós-graduação. É um retrocesso histórico, legitimado pela lei, pois o curso de Pedagogia desde sua criação luta pela sobrevivência da profissão do pedagogo como intelectual da educação.

Assim, para Libâneo (2007, p. 33) a Resolução CNE/CP nº 01/2006: 
Expressa uma concepção simplista e reducionista de pedagogia e do exercício profissional do pedagogo, decorrente da precária fundamentação teórica, de imprecisões conceituais, de desconsideração dos vários âmbitos de atuação científica e profissional do campo educacional. A Resolução (...) não contribui para a unidade do sistema de formação, não avança no formato da formação dos educadores necessários para a escola de hoje, não ajuda na elevação da qualidade dessa formação e, assim, afeta aspirações de elevação do nível científico e cultural dos alunos da escola de ensino fundamental"

Com a aprovação das Diretrizes Curriculares Nacionais para o Curso de Pedagogia licenciatura, através da Resolução CNE/CP n01 de 15 de maio de 2006, houve a necessidade de reformulação da matriz curricular a partir da extinção das habilitações, sendo que estas devem contemplar 3.200 horas de efetivo trabalho acadêmicas assim distribuídas:

I - 2.800 horas dedicadas às atividades formativas como assistência a aulas, realização de seminários, participação na realização de pesquisas, consultas a bibliotecas e centros de documentação, visitas a instituições educacionais e culturais, atividades práticas de diferente natureza, participação em grupos cooperativos de estudos;

II - 300 horas dedicadas ao Estágio Supervisionado prioritariamente em Educação Infantil e nos anos iniciais do Ensino Fundamental, contemplando também outras áreas específicas, se for o caso, conforme o projeto pedagógico da instituição;

III - 100 horas de atividades teórico-práticas de aprofundamento em áreas específicas de interesse dos alunos, por meio, da iniciação científica, da extensão e da monitoria. (BRASIL, 2006, p.2)

Atendendo a Resolução CNE/CP n0.01/2006, art.6ํ, a Estrutura Curricular do Curso de Pedagogia é composta a partir de 3 (três) núcleos de fundamentação. São eles:

Núcleo de Estudos Básicos - que tem como objetivo, por meio do estudo acurado da literatura pertinente e da realidade educacional, assim como por meio de reflexão e ações críticas e considerando a diversidade e a multiculturalidade da sociedade brasileira:

a) aplicação de princípios, concepções e critérios oriundos de diferentes áreas do conhecimento, com pertinência ao campo da Pedagogia, que contribuam para o desenvolvimento das pessoas, das organizações e da sociedade;

b) aplicação de princípios da gestão democrática em espaços escolares e não-escolares;

c) observação, análise, planejamento, implementação e avaliação de processos educativos e de experiências educacionais, em ambientes escolares e não-escolares;

d) utilização de conhecimento multidimensional sobre o ser humano, em situações de aprendizagem;

e) aplicação, em práticas educativas, de conhecimentos de processos de desenvolvimento de crianças, adolescentes, jovens e adultos, nas dimensões física, cognitiva, afetiva, estética, cultural, lúdica, artística, ética e biossocial;

f) realização de diagnóstico sobre necessidades e aspirações dos diferentes segmentos da sociedade, relativamente à educação, sendo capaz de identificar diferentes forças e interesses, 
de captar contradições e de considerá-lo nos planos pedagógico e de ensino aprendizagem, no planejamento e na realização de atividades educativas;

g) planejamento, execução e avaliação de experiências que considerem o contexto histórico e sociocultural do sistema educacional brasileiro, particularmente, no que diz respeito à Educação Infantil, aos anos iniciais do Ensino Fundamental e à formação de professores e de profissionais na área de serviço e apoio escolar;

h) estudo da Didática, de teorias e metodologias pedagógicas, de processos de organização do trabalho docente;

i) decodificação e utilização de códigos de diferentes linguagens utilizadas por crianças, além do trabalho didático com conteúdos, pertinentes aos primeiros anos de escolarização, relativos à Língua Portuguesa, Matemática, Ciências, História e Geografia, Artes, Educação Física;

j) estudo das relações entre educação e trabalho, diversidade cultural, cidadania, sustentabilidade, entre outras problemáticas centrais da sociedade contemporânea;

k) atenção às questões atinentes à ética, à estética e à ludicidade, no contexto do exercício profissional, em âmbitos escolares e não-escolares, articulando o saber acadêmico, a pesquisa, a extensão e a prática educativa; nacional.

I) estudo, aplicação e avaliação dos textos legais relativos à organização da educação

Núcleo de Aprofundamento e Diversificação de Estudos - Conteúdos voltados às áreas de atuação profissional priorizadas pelo projeto pedagógico e que, atendendo a diferentes demandas sociais, oportuniza, entre outras possibilidades:

a) investigações sobre processos educativos e gestoriais, em diferentes situações institucionais: escolares, comunitárias, assistenciais, empresariais e outras;

b) avaliação, criação e uso de textos, materiais didáticos, procedimentos e processos de aprendizagem que contemplem a diversidade social e cultural da sociedade brasileira;

c) estudo, análise e avaliação de teorias da educação, a fim de elaborar propostas educacionais consistentes e inovadoras.

Núcleo de Estudos Integradores - Visa proporcionar o enriquecimento curricular e compreende participação em:

a) seminários e estudos curriculares, em projetos de iniciação científica, monitoria e extensão, diretamente orientados pelo corpo docente da instituição de educação superior;

b) atividades práticas, de modo a propiciar vivências, nas mais diferentes áreas do campo educacional, assegurando aprofundamentos e diversificação de estudos, experiências e utilização de recursos pedagógicos;

c) atividades de comunicação e expressão cultural.

\section{CONSIDERAÇÕES FINAIS}

A partir das análises dos marcos legais que nortearam os cursos de Pedagogia percebemos que houve, desde a sua criação até hoje, uma incerteza sobre o propósito e a função do pedagogo, o que influenciou o desenvolvimento da licenciatura em Pedagogia, fazendo com 
que esta ocupasse um lugar periférico no contexto das licenciaturas, porque eram percebidas como cursos de segunda categoria.

O Parecer CFE no. 252/69 e a Resolução CFE 2/69 tentaram definir de uma forma mais clara a função do Pedagogo, extinguindo o grau de bacharel, mantendo a formação de professores para o Ensino Normal e introduzindo oficialmente as habilitações para formar os especialistas responsáveis pelo trabalho de planejamento, supervisão, administração e orientação educacional. Porém entendemos que a identidade do pedagogo ficou mais fragilizada, uma vez que houve uma fragmentação do profissional diante das possibilidades das habilitações serem concluídas isoladamente umas das outras, além do fato de ser permitido a todos os licenciados, independente dos cursos, essa complementação pedagógica.

A nova LDB 9394/96 e as Diretrizes Curriculares Nacionais para o curso de Pedagogia Resolução CNE/CP no01 de 15 de maio de 2006, não colaborou em nada com a identificação da identidade do pedagogo, uma vez o foco principal do curso é a formação docente.

Diante desse vasto e contraditório campo de atuação do Pedagogo, percebemos que as legislações e diretrizes não foram suficientes para resolver os dilemas enfrentados em torno das especificidades da Pedagogia, assim como a função e atuação deste profissional, prevalecendo, portanto a indefinição da função do Pedagogo, fazendo necessário que questão da sua identidade seja trazida à continuidade do debate por meio das vias legais.

\section{REFERÊNCIAS BIBLIOGRÁFICAS}

1. AGUIAR, M. A. Institutos superiores de educação na nova LDB. In: I. Brzezinski (org). LDB interpretada: diversos olhares se entrecruzam. São Paulo: Cortez, 2003.

2. ARANTES, A.P.P; GEBRAN, R. A. Docência no Ensino Superior: Trajetórias e Saberes. Jundiaí, SP, Paco Editorial, 2013.

3. BRASIL. Congresso Nacional. Lei 4.024 de 20 de dezembro de 1961. Fixa as diretrizes e bases da Educação Nacional. Diário Oficial da União, Brasília, DF, 24 dez. 1961. Disponível em: <http://www6.senado.gov.br/legislacao/ListaTextolntegral.action?id=75529>. Acesso em: 09 jul. 2013.

4.

Congresso Nacional. Lei 5.540 de 28 de novembro de 1968. Fixa normas de organização e funcionamento do ensino superior e sua articulação com a escola média, e dá outras providências. Diário Oficial da União, Brasília, DF, 03 dez. 1968. Disponível em: <http://www.planalto.gov.br/ccivil_03/Leis/L5540.htm>. Acesso em: 09 jul. 2013.

5. _ C C Congresso Nacional. Lei 9.394 de 20 de dezembro de 1996. Estabelece as diretrizes e bases da educação nacional. Diário Oficial da União, Brasília, DF, 23 dez. 1996. Disponível em: <http://www.planalto.gov.br/ccivil_03/Leis/L9394.htm>. Acesso em: 09 jul. 2013.

6. _. Decreto n. … 3.276, de 06 de dezembro de 1999. Dispõe sobre a formação em nível superior de professores para atuar na educação básica, e dá outras providências. Diário Oficial da União, Brasília, DF, 08 dez. 1999. Disponível em: <http://www6.senado.gov.br/legislacao/ListaTextolntegral.action?id=215368>. Acesso em: 09 jul. 2013.

7. . Ministério da Educação. Conselho Federal de Educação. Parecer n.252/69. Estudos 
pedagógicos superiores. Mínimos de conteúdo e duração para o curso de graduação em pedagogia. Relator: Valnir Chagas. Documenta, Brasília. (1-100), p.101-117.

8. _ Conselho Federal de Educação. Conselho Pleno. Parecer 05/2005. Relatoras: Clélia Brandão Alvarenga Craveiro e Petronilha Beatriz Gonçalves e Silva. 13 dez. 2005. Disponível em: < http://portal.mec.gov.br/cne/arquivos/pdf/pcp05_05.pdf>. Acesso em: 09 jul. 2013.

9. - Ministério da Educação. Conselho Federal de Educação. (1972) Parecer n.867/1972. Relator: Valnir Chagas. Documenta, Brasília. (1-140), p.339-341.

10. . Ministério da Educação. Conselho Federal de Educação. Resolução no. 2 de 12 de maio de 1969. Estabelece os conteúdos e a duração do Curso de Graduação em Pedagogia. In: SCHUCH, Vitor Francisco (org.). Lei de Diretrizes e Bases da Educação Nacional e o Magistério. 4 ed. Porto Alegre: Livraria Editora Sulina, 1972.

11. .Ministério da Educação. Conselho Pleno. Resolução $n$ o. 01 de 30 de setembro de 1999. Dispõe sobre os Institutos Superiores de Educação, considerados os Art. 62 e 63 da Lei 9.394/96 e o Art. 9o, § 2o, alíneas "c" e "h" da Lei 4.024/61, com a redação dada pela Lei 9.131/95. Disponível em: <www.pen.uem.br/diretrizes/Resol_CNE-CP_1999_001.doc>. Acesso em: 09 jul. 2013.

12. . Conselho Nacional de Educação. Conselho Pleno. Resolução no. 01 de 15 de maio de 2006. Institui Diretrizes Curriculares Nacionais para o Curso de Graduação em Pedagogia, licenciatura. Disponível em: <http://portal.mec.gov.br/cne/arquivos/pdf/rcp01_06.pdf>. Acesso em: 09 jul. 2013.

13. BRZEZINSKI, I. Pedagogia, pedagogos e formação de professores: busca e movimento. Campinas, SP: Papirus, 1996.

14. CHAVES, E. O. C. O curso de Pedagogia: um breve histórico e um resumo da situação atual. In: Cadernos do CEDES. A formação do educador em debate. São Paulo, (1-2), 47-69, 1981.

15. DONATONI, A. R.; GONÇALVES, S. A. S. Pedagogia: os marcos históricos, a identidade profissional e as Novas Diretrizes Curriculares Nacionais. Revista Profissão Docente (Online), (7-15), p.01-08, 2009 Disponível em: http://www.revistajuridica.uniube.br/index.php/rpd/article/view/106 Acesso em: 05/07/2013.

16. LIBÂNEO, J. C. A pedagogia em questão: entrevista com José Carlos Libâneo. In: Olhar de professor, Ponta Grossa, (10-1), 11-33, 2007. Disponível em: http://redalyc.uaemex.mx/redalyc/pdf/684/68410102.pdf Acesso em: 06/07/2013.

17. MARTELLI, A; MANCHOPE, E. A história do curso de Pedagogia no Brasil: da sua criação ao contexto após LDB 9394/96. Revista Eletrônica de Ciências da Educação. (3-1), 01-21, 2004. Disponível em: http://revistas.facecla.com.br/index.php/reped/article/view/517 Acesso em: 05/07/2013.

18. PEREIRA, J. E. D. As licenciaturas e as novas políticas educacionais para a formação docente. In: Educação \& Sociedade. Campinas, (1-68), 109-125, 1999.

19. SAVIANI, D. A pedagogia no Brasil: história e teoria. Campinas, SP: Autores Associados, 2008.

20. SILVA, C. S. B. Curso de Pedagogia no Brasil: historia e identidade. $3^{\circ}$ ed. Campinas: Autores Associados, 2006. 
21. SOARES, S. T.; BETTEGA, M. O. Políticas públicas de formação docente e ação pedagógica no ensino superior. Cadernos do Professor. (1-1), 71-90. Disponível em: http://www.prograd.ufpr.br/admin/publicacoes/arquivos/1706101276801451cadernos_do_ professor_v1.pdf Acesso em: 04/08/2013. 